\title{
Development of an integrated workflow for pit slope pore pressure reconciliation
}

J Dowling Piteau Associates, USA

G Beale Piteau Associates, USA

P Haas Piteau Associates, USA

B Kaya Piteau Associates, USA

S Mak Piteau Associates, USA

LC Tejada Freeport-McMoRan Inc., USA

K Kramer Freeport-McMoRan Inc., USA

J Johnson Freeport-McMoRan Inc., USA

RE Zea Freeport-McMoRan Inc., USA

C Palmer Freeport-McMoRan Inc., USA

\begin{abstract}
Mine plan implementation for the Western Copper open pit at Morenci in Arizona requires an intense program of bedrock dewatering production pumping to support sinking of the pit and reduce impacts of groundwater on day-to-day mining. In addition, the pit slope design contains specific groundwater pressure targets which are generated for annualised increments of the mine plan by the slope design team. The mine dewatering program is therefore also utilised to accomplish depressurisation for slope management purposes. As part of the slope depressurisation process at Morenci an innovative workflow was developed to reconcile observed pit slope pore pressures against geotechnical targets and predicted depressurisation results. The integrated workflow has provided a valuable pit slope pore pressure management tool to the program. This paper presents a review of the integrated workflow.
\end{abstract}

Keywords: dewatering, depressurisation, piezometers, workflow, integration, targets

\section{Introduction}

The Morenci Copper Mine, operated by Freeport-McMoRan Mining, is in eastern Arizona on the lower south slope of the White Mountains. There have been various forms of active mining in the district since early in the 20th century. The current mine plan involves surface mining from several open pit areas that will eventually merge. Mine processing includes run-of-mine stockpile leaching, oxide heap leaching and a mill and concentrator facility for sulphide ore. The main open pit mining areas currently include the Garfield, Sun Ridge, Coronado, Shannon, Metcalf and Western Copper areas. The daily mining rate ranges from 750 to $1,000 \mathrm{Kt}$ per day of mainly ore. Figure 1 is a general location map of Morenci.

Recent (since the 1990s) mining of the main open pit areas at Morenci has involved sinking of multiple phases beneath pre-mining district groundwater levels. This has required implementation of proactive mine dewatering and pit slope depressurisation measures including production pumping wells, horizontal drains and pit floor sump pumping equipment in order to mitigate the impacts of groundwater inflow on mining operations. In general, successful mine plan implementation has depended on the success of the mine dewatering program. From 2015 onward a new phase of mining has been undertaken in the Western Copper open pit mining area involving multiple pushbacks, deepening and expansion. The associated geomechanical 
design criteria have required a significant program of pit slope depressurisation to accomplish prescribed groundwater levels and pit slope pore pressure regimes needed to support the desired design criteria. To ensure the depressurisation targets are met during each current and future year of the mine plan, Freeport-McMoRan implemented a workflow process to integrate the pit slope geomechanics and mine dewatering programs. The method has been successful and now is being applied and implemented at other mine branches where pit slope depressurisation is needed to support slope design and performance.

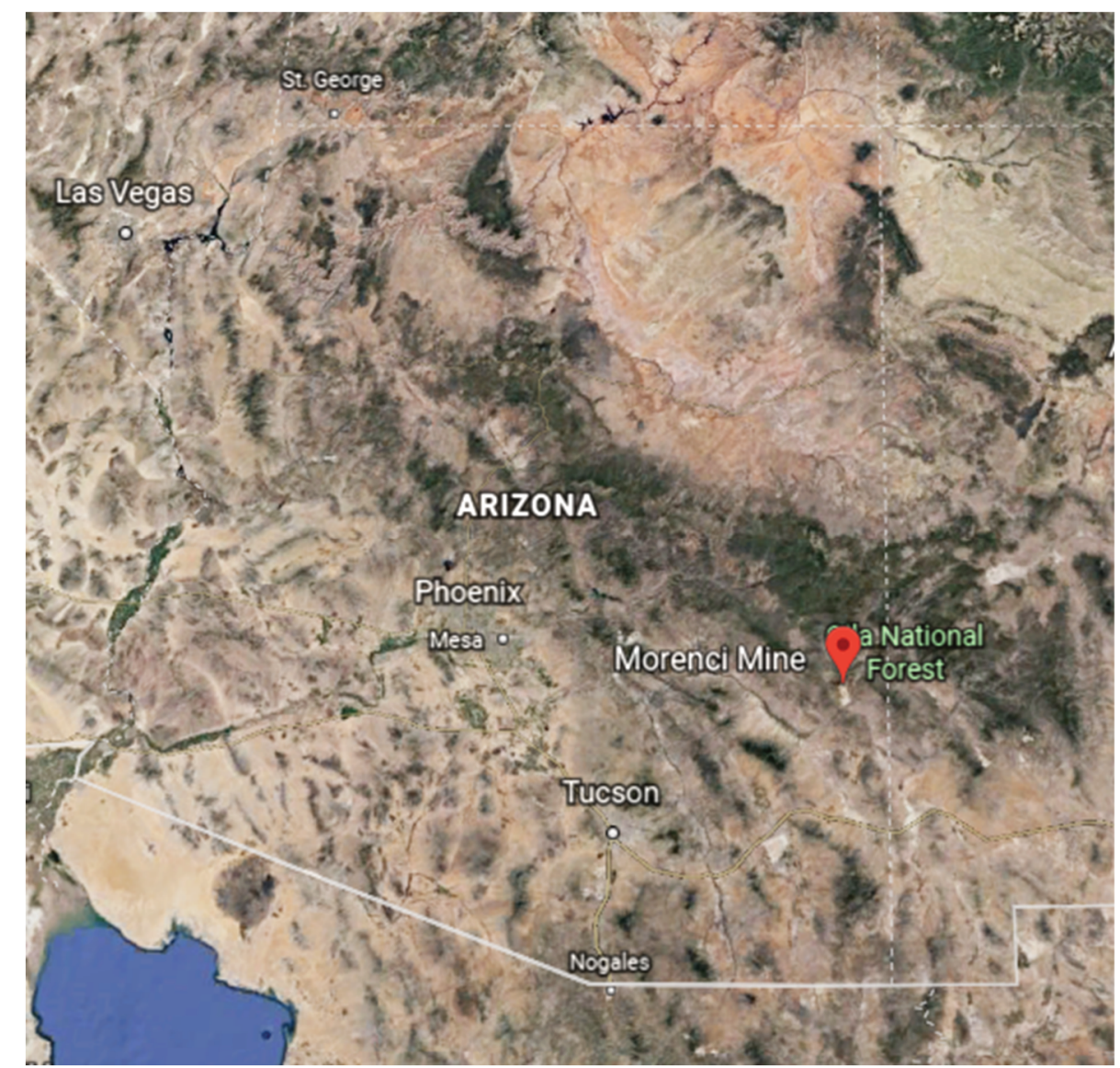

Figure 1 General location map of the Morenci mine

\section{$2 \quad$ Mine hydrogeology and dewatering overview}

\subsection{General hydrogeologic framework}

The Morenci mine complex is located on the south slope of the White Mountains within the Chase Creek drainage system. This is a side tributary of the San Francisco River which joins the Gila River a few kilometres south of Morenci.

The mining district is located within the Transition Zone, between the Colorado Plateau and the Basin and Range geologic provinces. Precambrian rocks, primarily granite, form the basement and were later covered by a sequence of Palaeozoic and Cretaceous sediments. Porphyritic intrusions comprising stocks, sills and dykes were emplaced in the Eocene. These intrusions include the monzonite porphyry, diabase, younger granite porphyry and the older granite porphyry. The Morenci area was then covered with a series of rhyolitic and basaltic volcanic events. Periods of faulting, uplift and erosion followed to dissect the district and form basin fill deposits. The major faults are separated into four sets based on orientation. In order from oldest to youngest, the fault sets are 1) east-west oriented, 2) northeast, 3) north-south, and 4) northwest.

The hydrogeology of the mine complex has been characterised during recent years (since about 2003) driven by the need to conduct bedrock production pumping in order to proactively lower the local groundwater 
table in advance of the sinking pit floor for various phases of mining. The ore deposits are relatively conductive to groundwater flow (average hydraulic conductivity ranges from $1 \times 10^{-5}$ to $1 \times 10^{-4} \mathrm{~cm} / \mathrm{sec}$ ) and significant groundwater inflow occurs to the working benches in the absence of ahead-of-time water table lowering with production wells.

Since 2004, Freeport-McMoRan Morenci has implemented mine dewatering with a program of Reverse Circulation (RC) hydrogeologic pilot hole drilling and testing using methods outlined by Beale \& Doubek (1992). High producing RC pilot holes are reamed and converted to production pumping wells, while the lesser producing holes are either abandoned or converted to piezometers for groundwater level monitoring. This is a standard approach for the development of a bedrock production pumping well program for mine dewatering (Beale \& Read 2013). The results of multiple programs across the district have shown that the granite porphyry ore deposit materials are pervasively conductive $\left(1 \times 10^{-4} \mathrm{~cm} / \mathrm{sec}\right.$ range $)$ and containing significant groundwater movement, whereas the regional sedimentary bedrock units are comparatively much less conductive $\left(1 \times 10^{-6} \mathrm{~cm} / \mathrm{sec}\right)$, containing minimal groundwater movement. Furthermore, hydraulic testing and dewatering experience shows there is no significant depth-dependent change in the conductive properties of the ore deposit units.

Groundwater moves toward the more fractured and conductive ore deposit materials by, a) flowing along discrete regional structural features, including the Chase Creek fault system, which connect to the broader system beyond the ore deposits, and b) local recharge from leakage to bedrock from low-grade stockpile facilities located close to the crest of many open pit sectors. This renders the groundwater to a low $\mathrm{pH}$ corrosive chemistry that often requires specialised pump well material specifications.

Historic open pit dewatering efforts at Morenci have included those at the Metcalf, Coronado, and Garfield open pit mining areas. A summary of the attained dewatering results is provided in Figure 2 and Table 1. As indicated, the total production pumping rate for each mining area, ranged from 30 to $95 \mathrm{~L} / \mathrm{s}$ produced from bedrock wells with individual flow rates typically in the 3 to $10 \mathrm{~L} / \mathrm{s}$ range, with the higher flowing wells almost always in the granite porphyry materials.

Table 1 Summary of historic dewatering production pumping rates achieved in selected Morenci mining areas

\begin{tabular}{lllll}
\hline Open pit & $\begin{array}{l}\text { Average } \\
\text { pumping } \\
\text { rate (L/s) }\end{array}$ & $\begin{array}{l}\text { Availability } \\
\mathbf{( \% )}\end{array}$ & Hydrogeology type & $\begin{array}{l}\text { Drawdown } \\
\text { achieved }(\mathbf{m})\end{array}$ \\
\hline Metcalf & 30 & 60 & Mild compartmentalised & $90-185$ \\
Coronado & 20 & 30 & Strong compartmentalised & $60-120$ \\
Garfield & 95 & $40-60$ & Interconnected & $120-245$ \\
\hline
\end{tabular}

Due to the distribution of higher conductivity and better producing wells coinciding with the porphyry Granite the strategy for dewatering well placement has mostly involved in-pit locations within or near the active mine operating areas. This is required so that the wells can intercept and produce flow from the conductive rock units where there is active groundwater flow and movement. However, in-pit production wells are always challenging to maintain and operate because they interact with mining. Therefore, the historic well-run times or 'availability' was generally lower than desired, in the 30-50\% range (see Table 1). Hence, in most historic cases at Morenci, while some level of benefit was gained from dewatering efforts, wet mining conditions were normally experienced. 


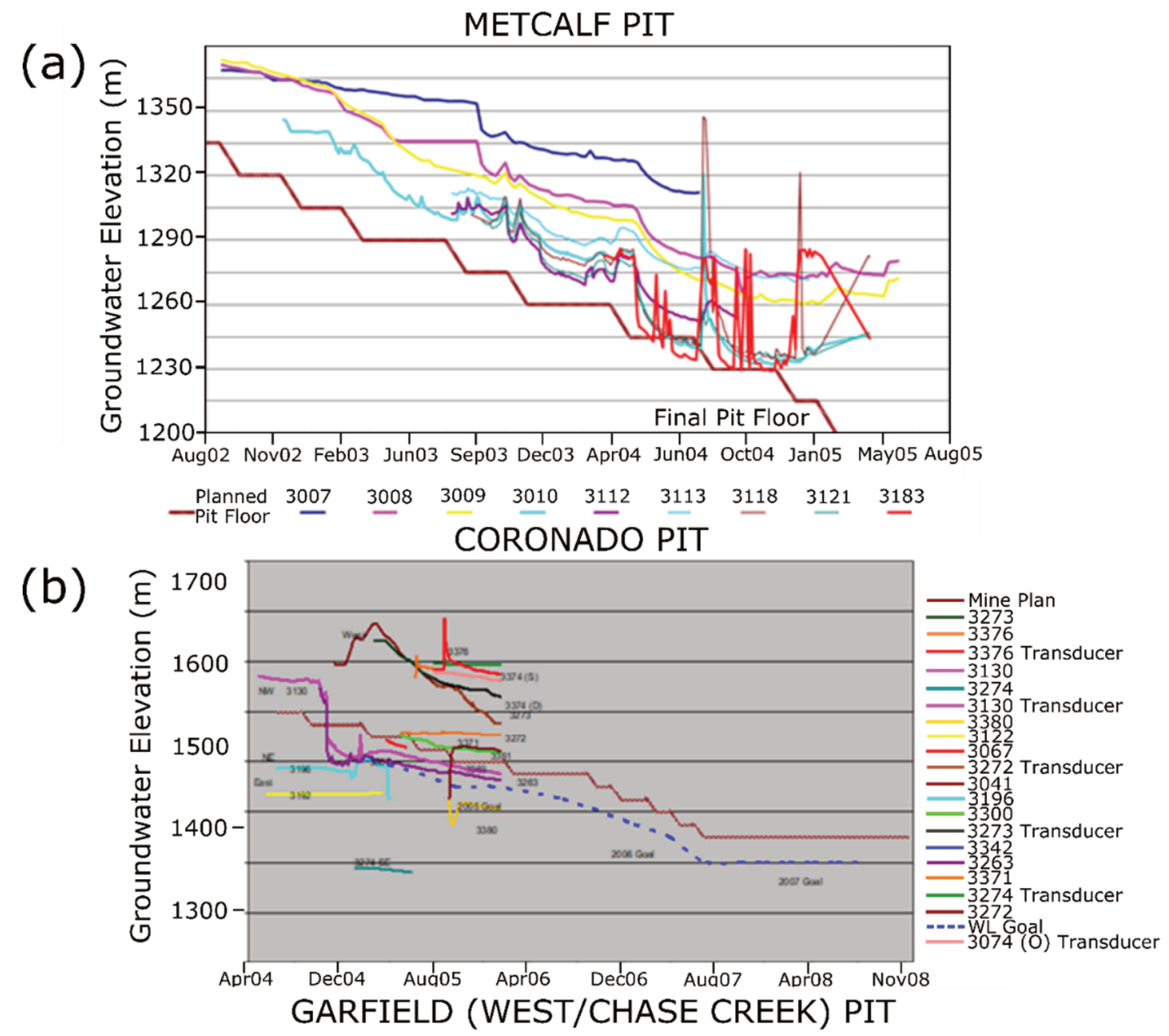

(c)

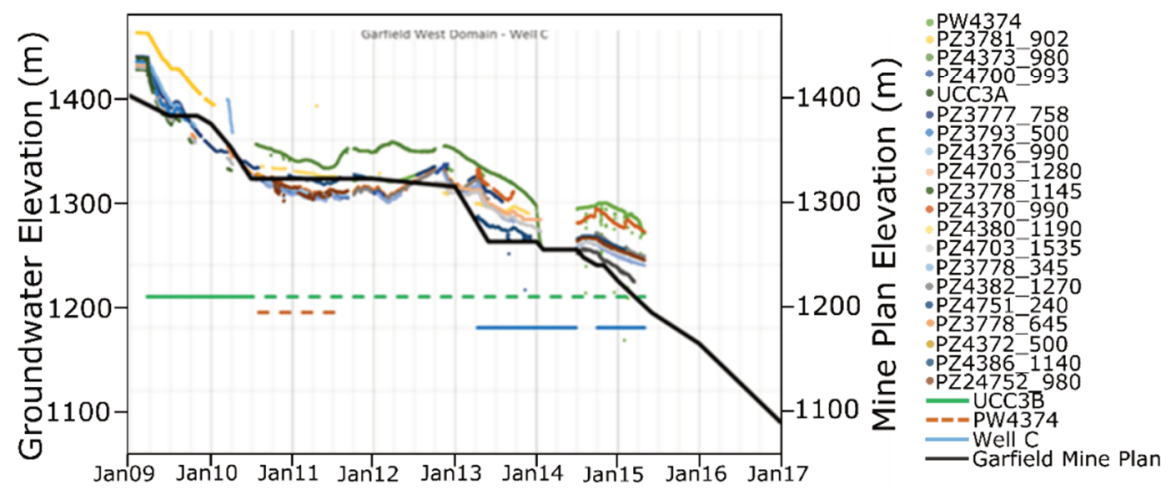

Figure 2 Historic piezometric response hydrographs ( $x$-time, $y$-groundwater elevation) to dewatering pumping of the (a) Metcalf, (b) Coronado; (c) Garfield mining areas at Morenci

\subsection{Western Copper dewatering requirements}

The Wester Copper open pit mining area is the southernmost open pit at Morenci and the furthest down gradient in the Chase Creek drainage. A series of pushbacks were planned for Western Copper commencing in 2015 and through the life-of-mine (LOM) to 2036. The general plan involves multiple pushbacks of the east, northwest and southwest walls and sinking of the pre-existing pit floor from 1,158 metres above sea level (masl) to 850 masl. 
Prior to commencement of renewed mining in Western Copper bedrock groundwater levels in the lower pit were coincident with the pit floor elevation of approximately 1,125 masl). Based on a pre-existing baseline piezometer network, bedrock groundwater levels in the east and west pit walls were considerably more elevated, ranging from 1,350 to 1,460 masl, maintained by the surrounding regional bedrock hydraulic gradients and also via recharge from stockpile leaching above the crest areas in these sectors.

Before commencement of the pushback sequence, maintenance dewatering (or removal of ongoing seepage) occurred from the Wester Copper pit floor, via pumping from the 'Dispatch' sump. This also was used to stage pump process solution storage and pumping from the surrounding leach stockpiles. Therefore, the rate of bedrock inflow and pumping. It was not possible to separate and quantify from the overall throughput of the sump.

The initial phase of mining in Western Copper involved a pushback of the east wall, commencing at a crest elevation of 1,460 masl and sinking down to the 990 masl elevation over a period of five years with an average sink rate of six benches or $90 \mathrm{~m}$ per annum. Given the existing conditions, planned mining involved sinking down through the groundwater system over most of the elevation range of the pushback. Preliminary hydrogeologic and dewatering evaluation indicated that a groundwater pressure regime would develop behind the walls of the active pushback as a result, and, significant groundwater inflow to the operation would occur as the bench elevation approached and sunk below the pre-existing pit floor.

Using the general analogue of Metcalf, Coronado and Garfield and given comparable hydrogeologic conditions, it was tentatively estimated that groundwater inflow rates to the east sector pushback would exceed $65 \mathrm{~L} / \mathrm{s}$ and be much higher for the entire Western Copper pit development. Additionally, slope design analysis completed by the Freeport-McMoRan Geomechanics team using the FLAC3D code indicated that achieving prescriptive groundwater levels and pore pressure conditions would be needed on an annualised basis during pushback implementation in order to maintain a target overall slope Factor of Safety (FoS) acceptance criteria of 1.2 or above.

At commencement of east wall pushback mining in 2016 a preliminary layout of phased dewatering production pumping wells was designed to support mining operations. The generalised objectives included: 1) minimising groundwater inflow to the operating benches and reducing the impact of groundwater on general mine-ability of the pushback, and 2) creating groundwater pressure reduction behind the wall and the toe of the pushback to support the pit slope design and performance. The initial layout of dewatering production wells is shown in Figure 3 and included:

- In 2017 an initial arrangement of four production wells - three in the south and one to the north across the east wall - collared behind the active cut or in the pit floor, with initial yields ranging from 3 to $30 \mathrm{~L} / \mathrm{s}$.

- In 2018, a second round of two production wells implemented in the pit floor to the south and west of the main pushback footprint, with initial yields ranging from approximately 4 to $40 \mathrm{~L} / \mathrm{s}$.

- A program of opportunistic horizontal drain drilling from available bench locations, again from north to south across the east wall.

- A program of approximately 14 multiple-level, vibrating wire piezometer holes distributed from south to north across the east wall with most located on the crest or in the middle slope sectors behind the active cut. 


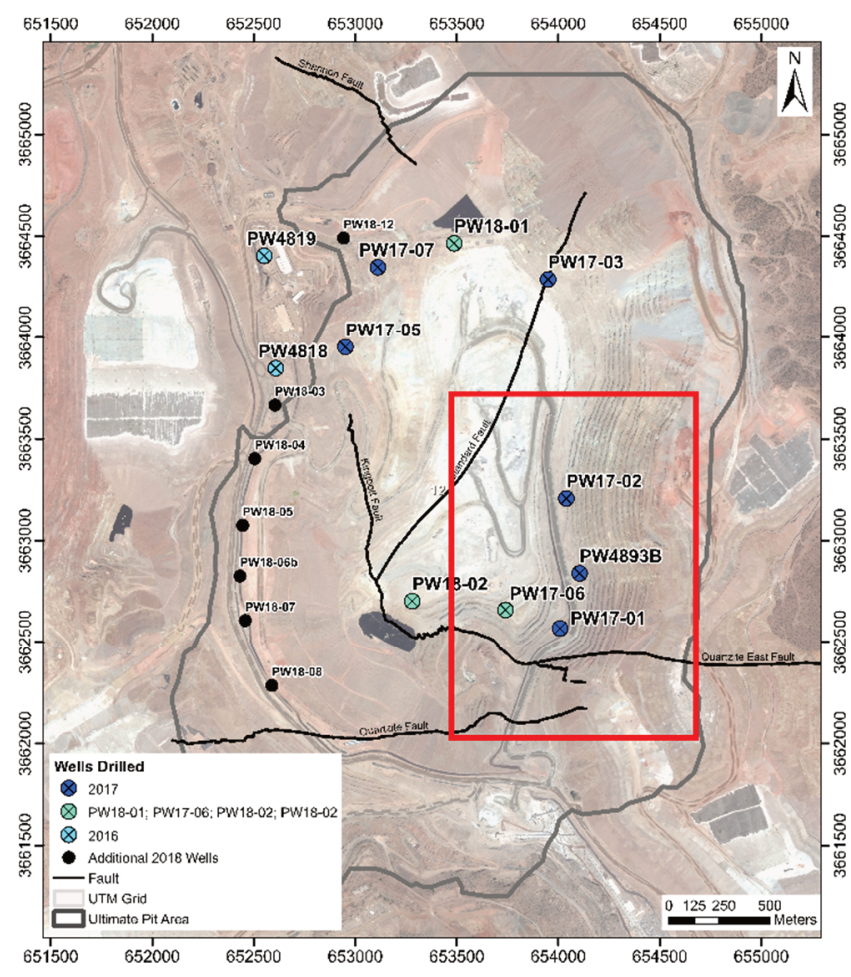

(a)

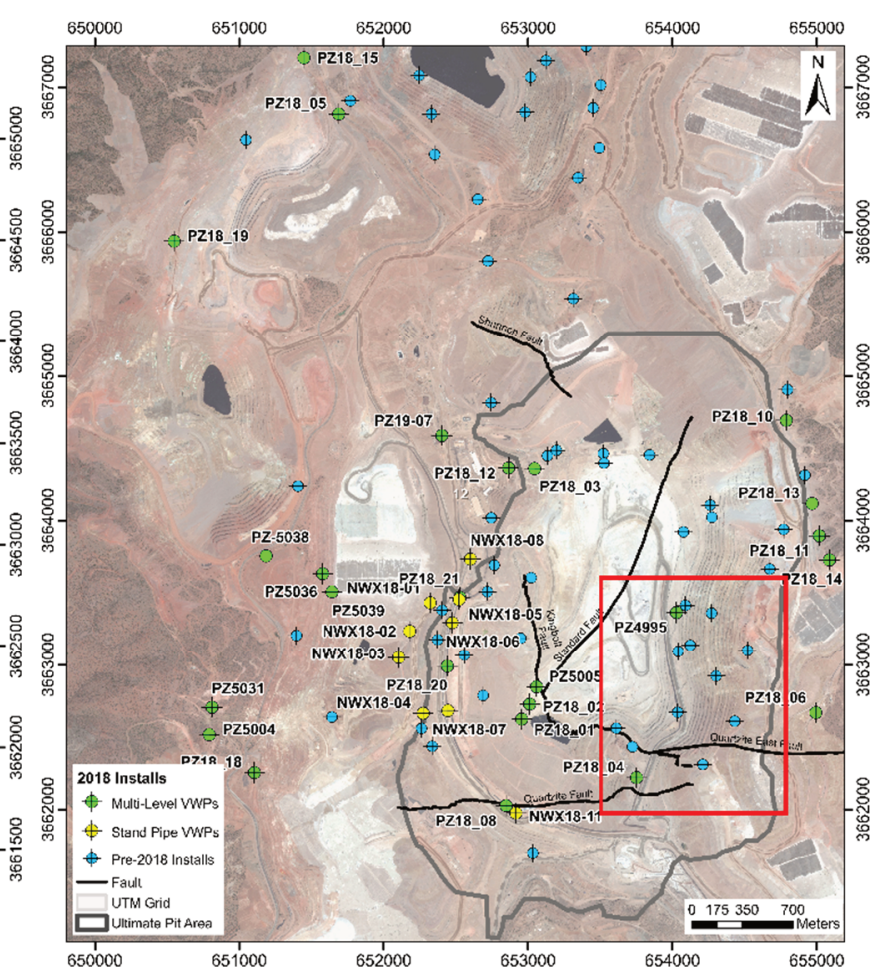

(b)

Figure 3 Initial arrangement of (a) Dewatering wells; (b) Piezometers for Western Copper, including the east wall pushback

While a general program of production pumping would have likely been adequate to accomplish reasonable mitigation of wet working benches for most of the planned pushback, the requirement for prescribed pore pressures in the annual pushback wall necessitated an additional level of rigour be established for dewatering planning, implementation and operation (Dowling \& Tejada, pers. comm., 2016-2019). This was considered necessary in order to ensure the pore pressure targets were met and the FoS of the pushback wall was not reduced below the design requirement due to groundwater. In order to ensure that the general mine dewatering plan would be adequate to accomplish the depressurisation targets required in the pushback design, a fully integrated dewatering and geomechanical workflow was implemented and used to analyse and optimise the program.

\section{$3 \quad$ Integration of dewatering and slope geomechanics workflows}

\subsection{Overview}

The development of the integrated workflow developed to manage the mine dewatering and pit slope depressurisation for the east wall of Western Copper included participation of the Mine Hydrogeology and Dewatering, Geomechanics, and Mine Operations, with support from consultants. This was validated by a peer review process (Morenci Task Force Meetings). The main elements included:

- Prediction of expected hydrogeologic responses from the initial layout and planned addition of dewatering wells, using a predictive 3D groundwater flow model.

- Preparation of a FLAC3D pit slope design model to evaluate slope stability and to establish annualised depressurisation targets required to support the desired FoS criteria. 
- Integration of groundwater flow model predictions and the FLAC3D depressurisation targets to evaluate domains and time frames where the dewatering system would be expected to create compliant and non-compliant conditions relative to the depressurisation targets.

- Implementation of a targets tracking system for the piezometer network in the east pushback allowing field conditions to be reconciled with transient depressurisation and mine dewatering requirements.

- Routine reporting of observed conditions relative to depressurisation and dewatering targets.

\subsection{Dewatering system design and prediction}

A 3D groundwater flow model was constructed by the Freeport-McMoRan Hydrogeology and Dewatering team to support mine dewatering and pit slope depressurisation decision-making. It was constructed using the MODFLOW SURFACT code and the domain encompassed an area extending across the entire Morenci district to natural hydrogeologic boundaries beyond the immediate mine area. A detailed area of refinement was centred over the Western Copper pit area allowing the geology of this mining area to be included at the scale of the mine geology model. Additional to the mine geology, all major structures were included as discrete zones of material property within the geologic framework. The leach stockpiles on the crest areas of the east and west sectors were represented as zones of increased bedrock recharge beneath the footprint of each facility. A summary of the model grid design and the transient calibration targets is shown in Figures 4 and 5 .

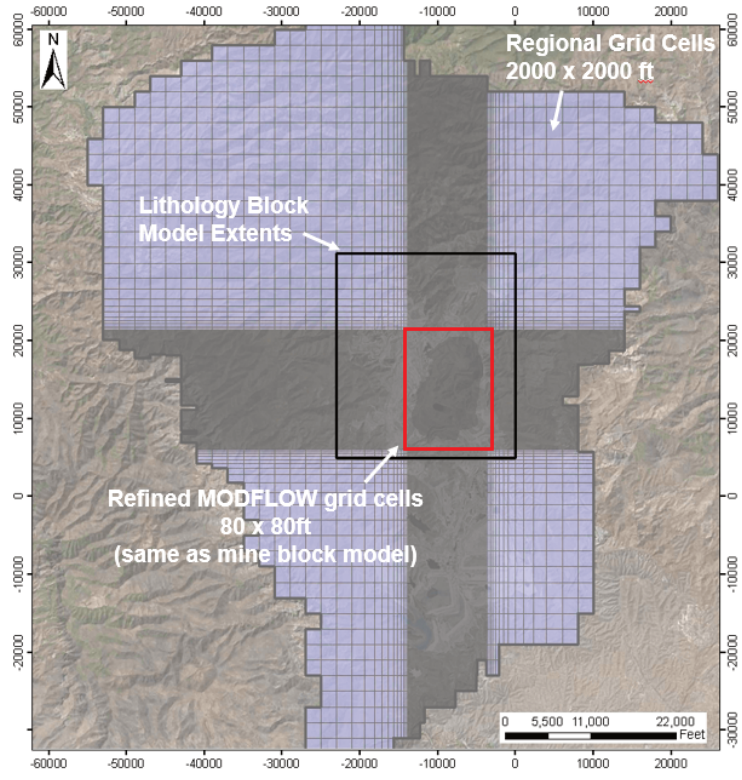

(a)

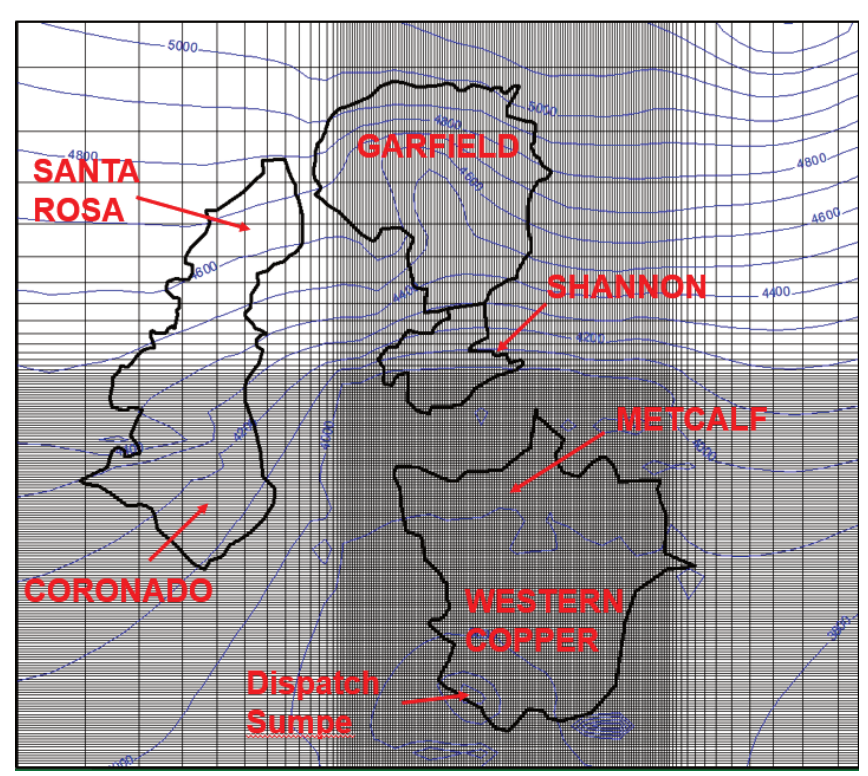

(b)

Figure 4 Groundwater flow model domain (a) With detailed grid; (b) Centred on Western Copper mining area 


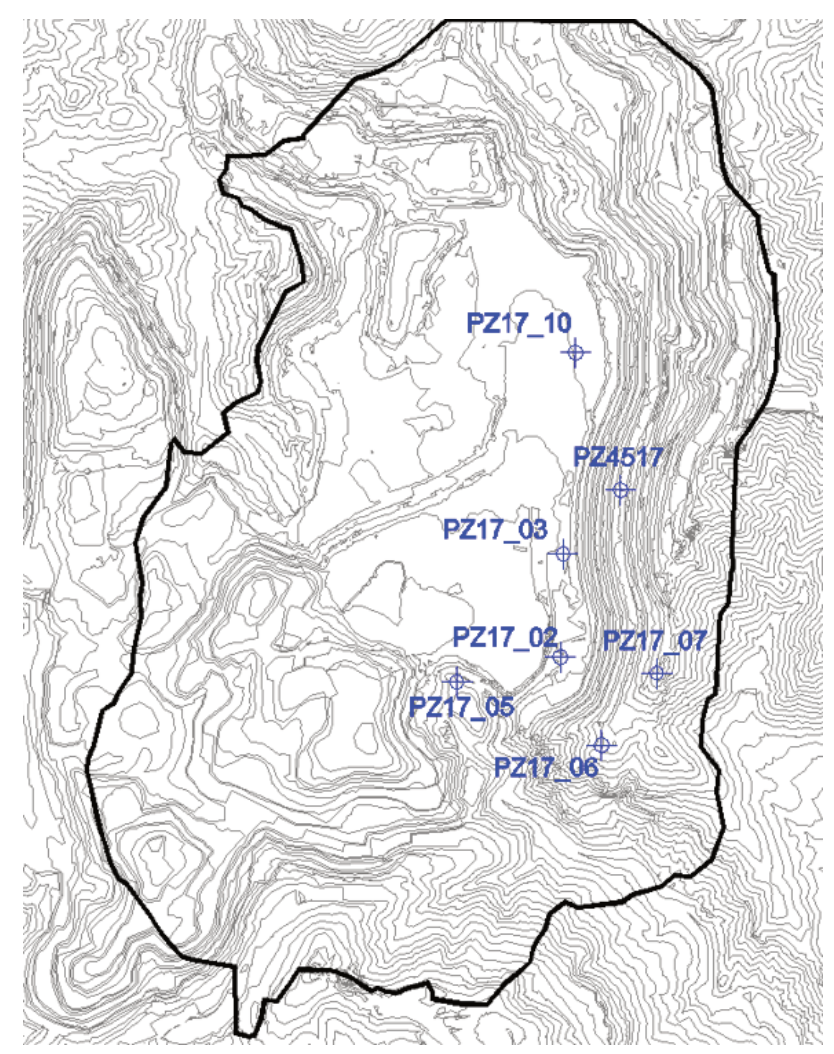

Figure 5 Western Copper piezometer locations used in the transient model calibration

The groundwater model was calibrated to historic piezometric levels in the Western Copper area, plus transient piezometric responses to mining and early stage dewatering production pumping. An illustration of the transient calibration result is shown in Figure 6. After reasonable calibration was achieved, the model was configured into predictive mode. The annual mine plan was incorporated into the predictions with each annual planned pit geometry represented with drains allowing passive seepage at the face of each cut. The existing and planned additional program of dewatering production pumping wells for the east wall and the broader Western Copper pit also was implemented on annual time steps. Careful coordination with the mine dewatering team plus mine planning and operations was completed to ensure the program of future dewatering wells included in the predictions only involved locations that the mine could commit to making available for the dewatering program. Further, a realistic schedule of future well drilling, construction and operation was implemented within the predictive set-up.

The groundwater model was run forward in predictive mode through the LOM with the mine plan implemented on annual increments and dewatering wells added at more discrete time intervals. The program of pre-existing and planned additional dewatering wells was activated within the predictions at the locations agreed upon with mine planning and according to the projected schedule for construction, commissioning and operation. All the wells were simulated using assigned rates of flow, based on knowledge and experience of pre-existing bedrock wells and assuming an average availability of $80 \%$.

Three-dimensional groundwater pressure grids were calculated from the predictive model for annual increments of the mine plan. These were used to evaluate groundwater pressure distributions behind the pit walls and pit floor, and the expected amount of groundwater system response during mine plan implementation to ongoing pit floor sinking and the dewatering production pumping efforts. Annualised 3D pressure grids were exported from the groundwater model and compared with annual depressurisation targets generated from FLAC3D, as is further discussed later. 
PZ17_02WC_780

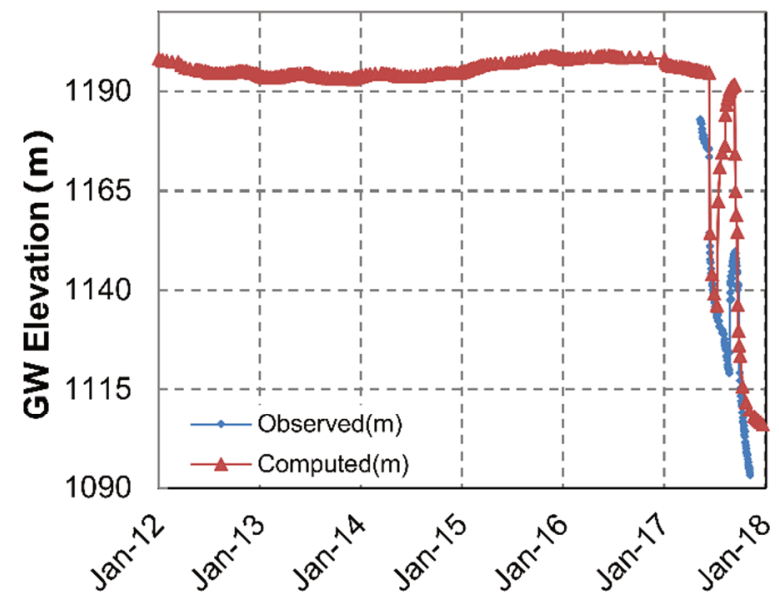

PZ17_02WC_1390

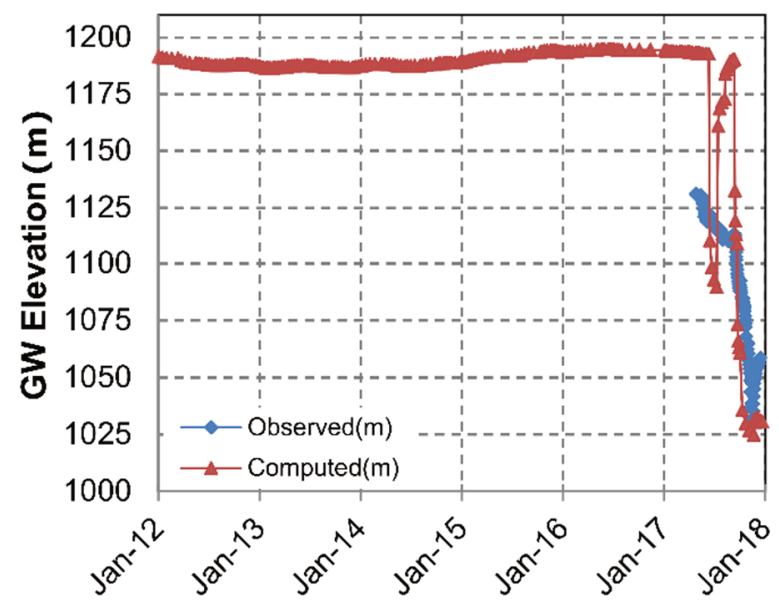

PZ17_02WC_885
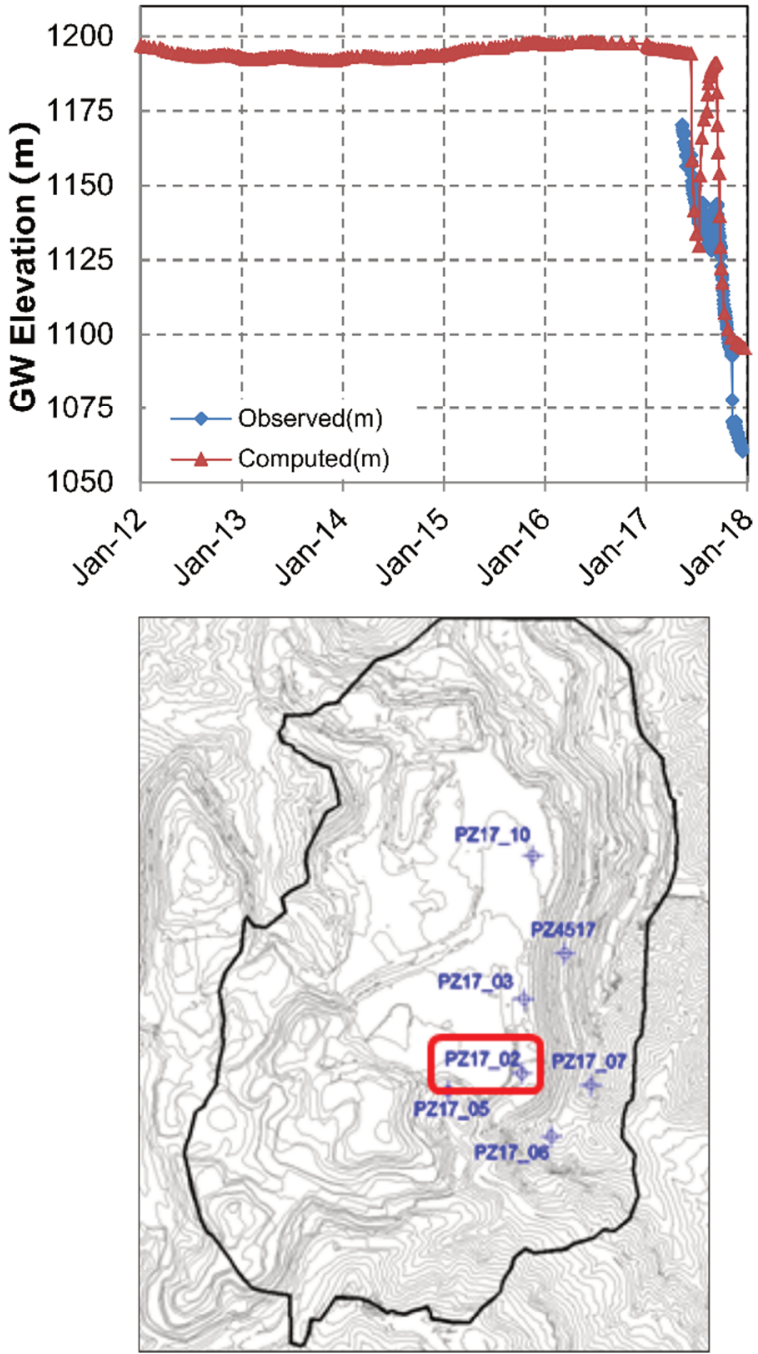

Figure 6 Example transient calibration plots showing observed (blue) and modelled (red) groundwater responses

\subsection{FLAC3D slope design and depressurisation targets}

A FLAC3D model was constructed for the east wall by the Freeport-McMoRan Geomechanics team. It was used to evaluate the design and stability of the mine plan for each planned year of mining. The model was set up with an assigned groundwater pressure grid using FLAC3D settings. Cases were considered with dry (no groundwater) conditions as a reference case and for scenarios where a 3D distribution of groundwater pressures was present. The initial condition for groundwater was assigned using the 3D groundwater flow model and the site data as a guide. For each year of the mine plan simulated with the presence of groundwater, manual adjustments were made to the pressure grid where needed to maintain the computed FoS at the minimum acceptable criteria of 1.2. Subsequently, the annual FLAC3D pressure grids were exported and used to compare against the expected or achievable groundwater pressure conditions predicted by the groundwater flow model.

\subsection{Comparison of dewatering performance and depressurisation targets}

A 'heat map analysis' was developed for comparing the predicted groundwater pressure regimes based on the current and anticipated future dewatering system layout and mine plan, with, the depressurisation targets required to maintain the minimum acceptable FoS. 
For each year of the future mine plan the FLAC3D pore pressure grid was three-dimensionally draped onto the corresponding Modflow groundwater pressure grid. An interpolation algorithm was used to create rasters from both grids to compute the difference in pressures between them. A simple system of scaled colours was then used to express the difference, with cool colours used to show where the 3D groundwater model pressures were lower than FLAC3D, signifying that the mine dewatering system and general groundwater system responses to mine plan implementation would render pore pressure conditions compliant or better than compliant with the requirements for slope design. In a similar way, warm colours were used to show areas where groundwater pressures were predicted to be higher than acceptable or noncompliant with the requirements of the slope design. The general workflow for generating the heat analysis is illustrated in Figure 7.

\section{GROUNDWATER FLOW MODEL PORE PRESSURE OUTPUT} Point Data

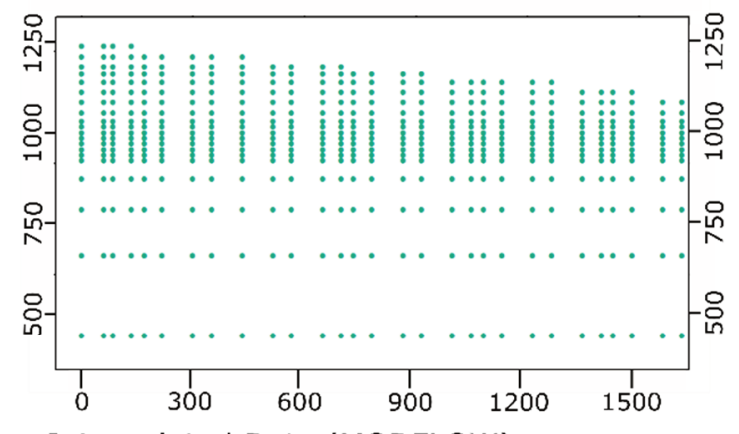

Interpolated Data (MODFLOW)

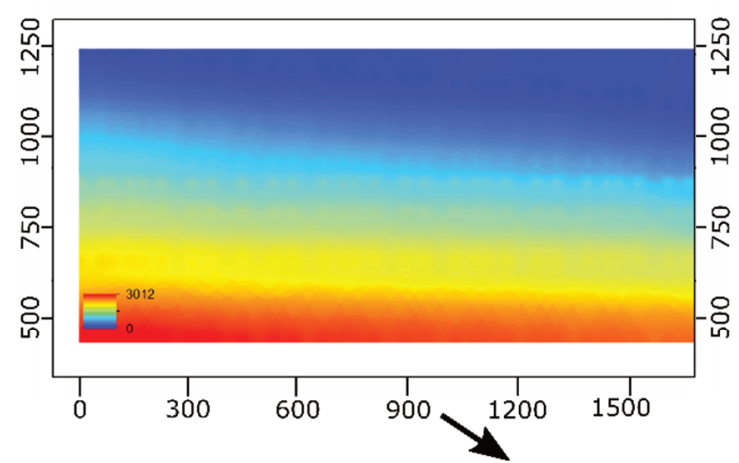

SLOPE STABILITY MODEL

TARGET PORE PRESSURE

\section{Point Data}

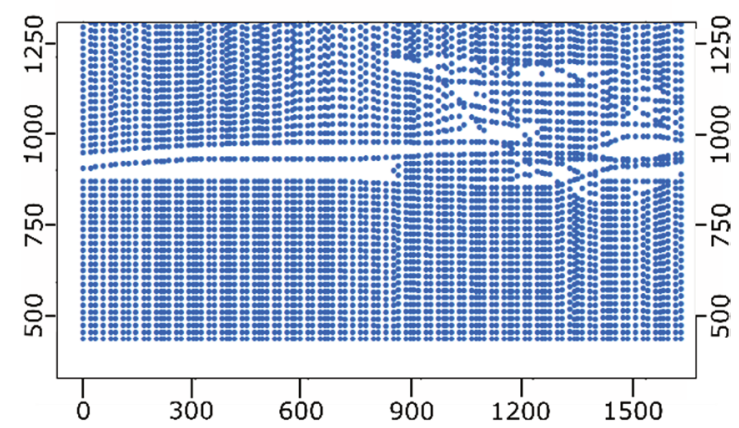

Interpolated Data (FLAC 3D)

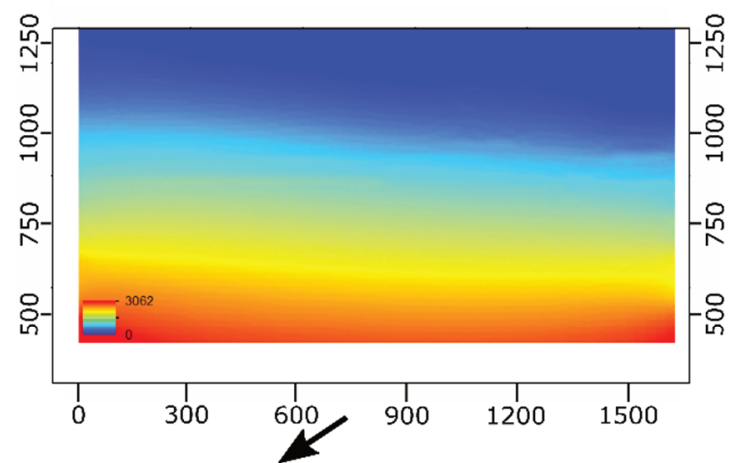

Difference Raster (MODFLOW - FLAC 3D)

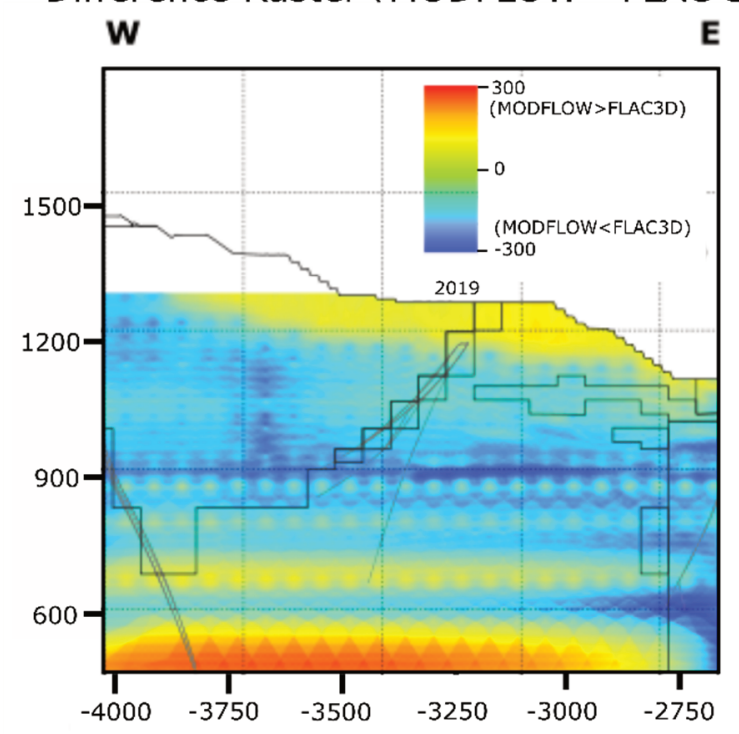

Figure 7 Workflow diagram for heat map generation from groundwater model and FLAC3D pore pressure grids 
The results of the heat analysis were processed onto three 'control' cross-sections through the east pushback of Western Copper for annual increments of the future mine plan. As part of evaluating the level of benefit from the dewatering program, pertaining to generating groundwater pressure conditions to support the slope design, cases were run with 1 ) the assumption of mining without any proactive pit dewatering measures, and 2) the planned mine dewatering program implemented. An illustrative montage of heat map analysis for a selected control cross-section are shown in Figure 8.
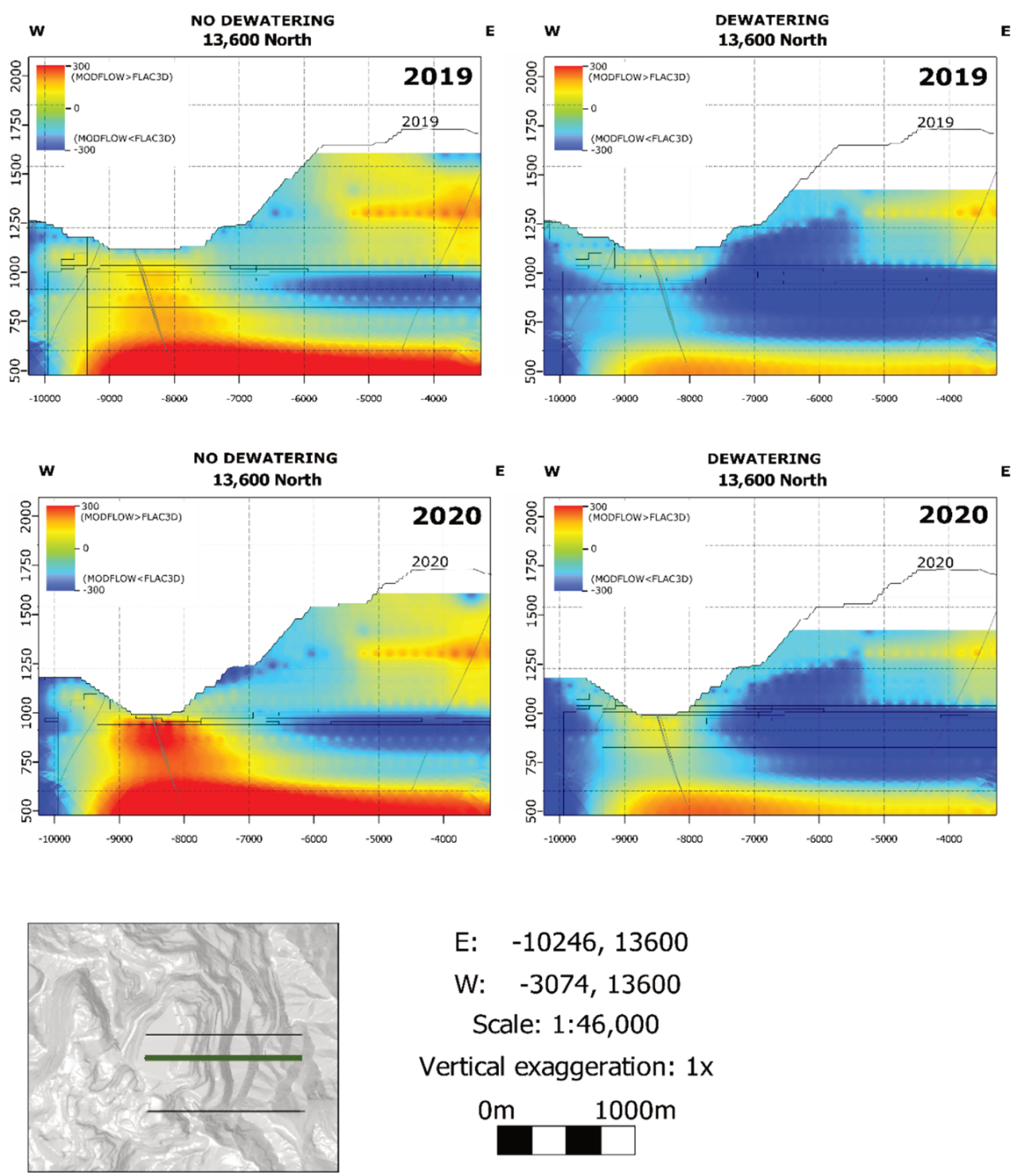

$$
\begin{gathered}
\text { E: } \quad-10246,13600 \\
W: \quad-3074,13600 \\
\text { Scale: } 1: 46,000
\end{gathered}
$$

Vertical exaggeration: $1 \mathrm{x}$

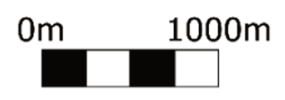

Figure 8 Heat map analysis for the east pushback for selected mining years 2018 (top) through 2020 (bottom)

From the heat map analysis, two important points become evident: 1) the benefit of the planned mine dewatering program is strongly evident, with the amount of compliant (cool colour) zones much more prevalent for the case where dewatering is implemented in the predictions, and 2) the planned dewatering program while beneficial, requires additional components in future years to adequately depressurise the toe of the planned pushback. The analysis suggested that groundwater pressures would be between 30 and $90 \mathrm{~m}$ higher, or out of compliance, compared to those needed for slope design purposes. With the benefit of this analysis, additional production pumping wells have been scheduled into the lower part of the pushback on a proactive, ahead-of-time basis in order to further depressurise the lower slope and toe of the future pushback. A lower slope dewatering bench and layout of toe area production pumping wells has been added to the dewatering system layout based on the heat map analysis results. 


\subsection{Piezometer network and performance reconciliation}

Reasonable confidence was placed in the groundwater flow model prediction of future hydrogeologic responses to planned dewatering efforts. Confidence was built based on the transient calibration process, the conceptual model and peer review. Through integration with the FLAC3D model, heat map analysis was used to indicate where the planned dewatering measures will likely create pore pressure ranges that comply and similarly do not comply with depressurisation requirements for slope design in future years. On this basis, additional dewatering measures were planned for future years targeting non-compliant zones, most notably toward the toe of the future pushback.

Given the importance of attaining depressurisation targets to pit slope performance, a piezometer network and tracking system was developed. The network is used to compare actual groundwater pressures and response trends to: a) the groundwater prediction of current and future pressure, b) the depressurisation target required for the current and future years of the mine plan, and c) a target for the current and future years dewatering system which is $75 \mathrm{~m}$ below (lower or less groundwater pressure) compared to the depressurisation target. The purpose for the dewatering target was to provide a contingency buffer to allow for hydrogeologic uncertainty and the possibility that periodic delay or downtime may occur within the operational execution aspects of the dewatering program. Given these normal risks within a mine dewatering program, setting dewatering targets to match current or future year depressurisation targets, may ultimately not accomplish the objectives for slope design.

All piezometer locations in the east wall pushback vicinity (and more broadly throughput Western Copper) were completed as multiple-level transducer completions with three or four placed and sealed in each piezometer hole at selected locations within the geologic sequence. For all transducer locations, a transient hydrograph was developed - see the illustrations provided in Figures 9 and 10. The hydrograph for each monitoring (transducer) location in the pit slope shows:

- The time series of actual measured (observed) groundwater elevation encompassing the historic period of record through current time.

- The groundwater flow model prediction of elevation head for historic, current and future years, extracted from the appropriate $x, y, z$ location in model grid.

- The depressurisation target expressed as elevation head for historic, current and future years in the mine plan, extracted from the appropriate $x, y, z$, location in the FLAC3D model mesh.

- The dewatering target expressed as the depressurisation target in elevation head with a contingency of $75 \mathrm{~m}$ subtracted.

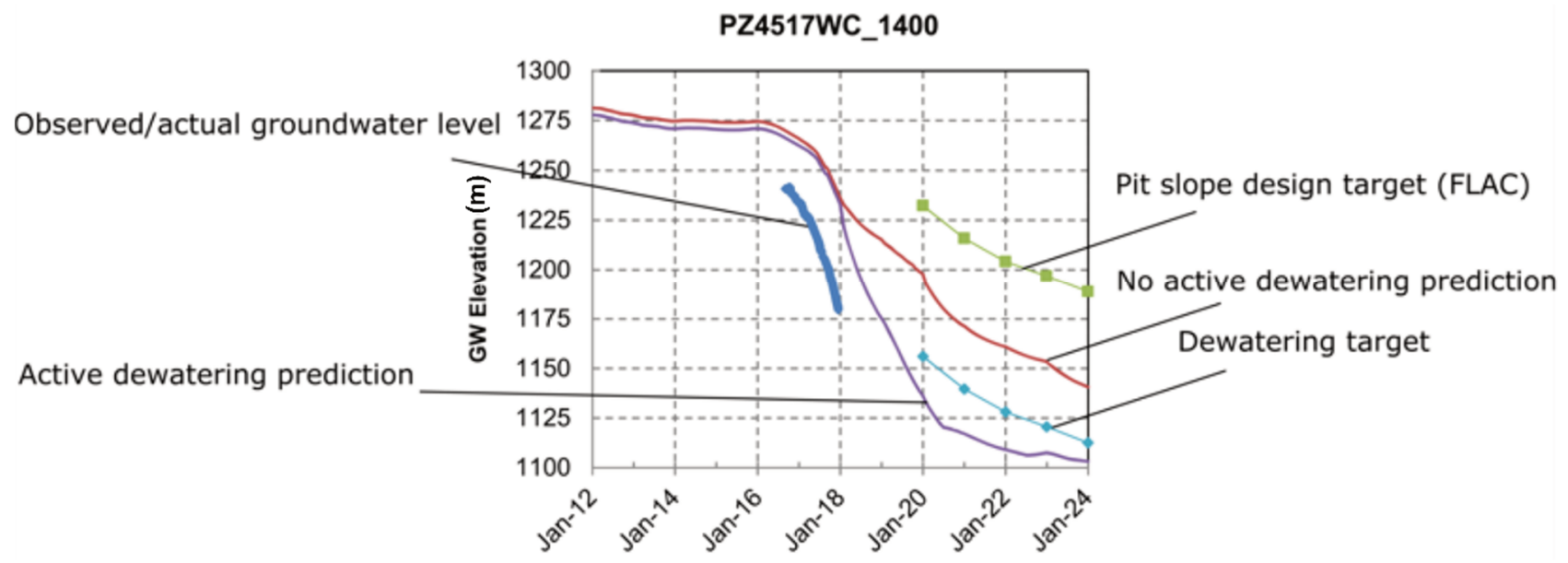

Figure 9 Dewatering and depressurisation tracking and validation with hydrograph plots 


\section{PZ17-03}

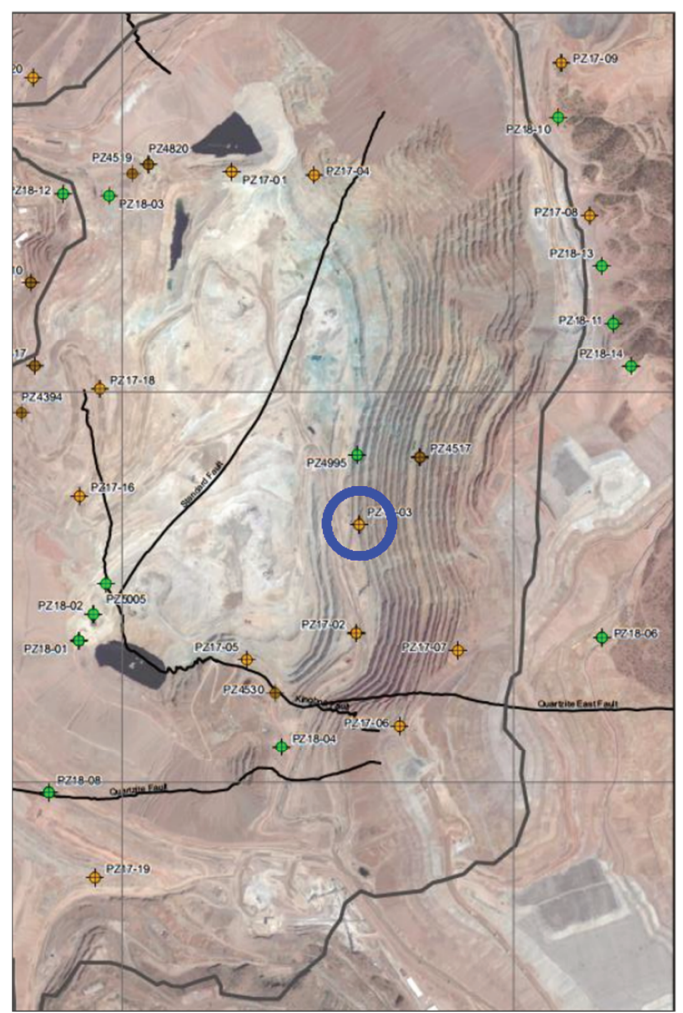

(a)
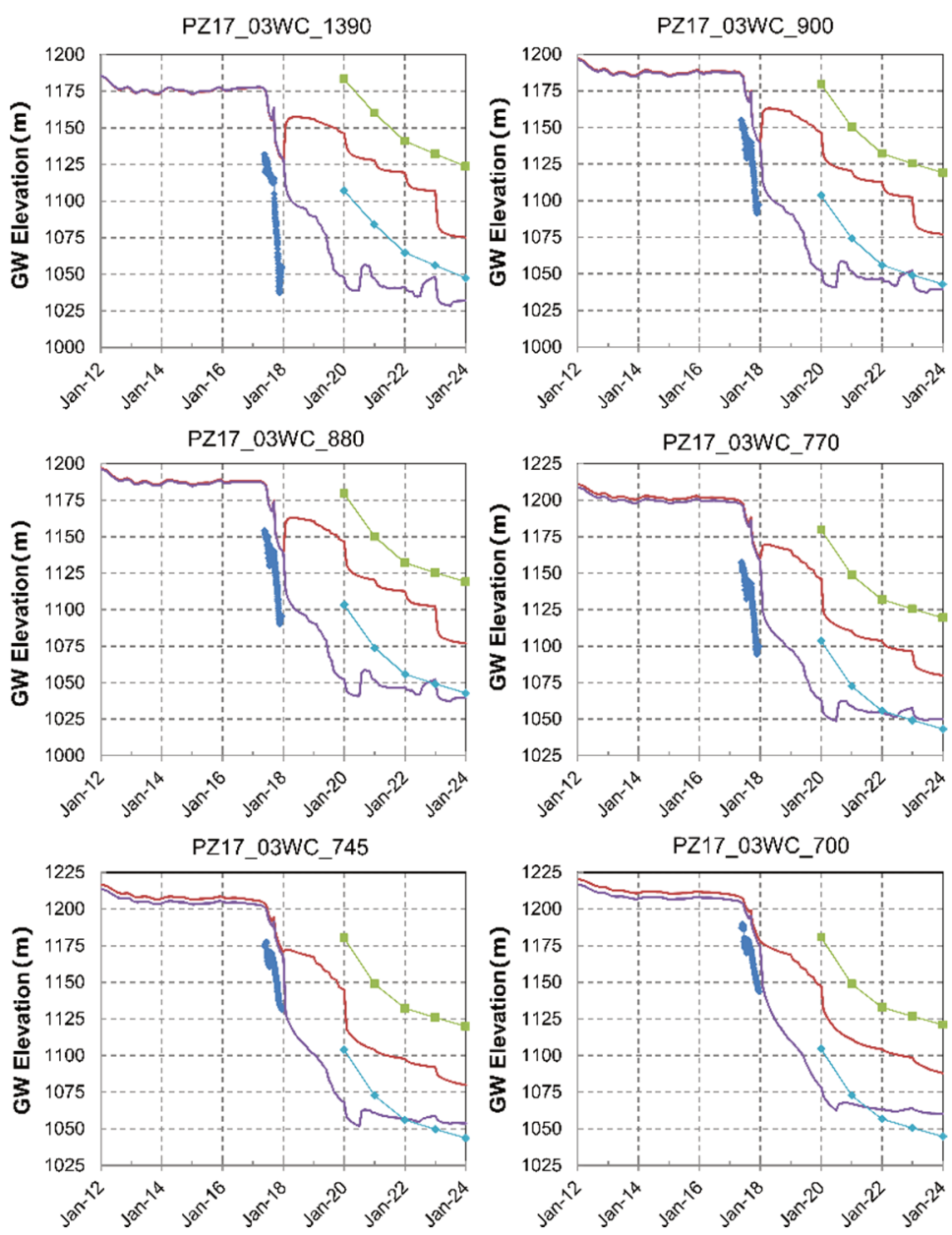

(b)

Figure $10 \quad$ (a) Example piezometer location with (b) Dewatering and depressurisation hydrograph reporting

With the above variables all plotted together, fully integrated tracking of the program is established with respect to mine dewatering and pit slope depressurisation for design. The plotting of the groundwater model prediction with the observation piezometer data builds additional confidence in the predictive results and the future projection of compliance with later year slope design. The plotting of the observational data with the depressurisation and dewatering targets confirms current time compliance and allows the trajectory of ongoing drawdown to be reviewed with later year depressurisation requirements. In this way, it is possible to proactively forecast potential future concerns and implement additional mine dewatering and pit slope depressurisation measures where needed to ensure compliant conditions are attained. As part of this, alarm levels are established for each transducer and used as the basis to trigger proactive action and intervention:

- A Level-1 (lowest) alarm is triggered where the current observed groundwater level is approaching or above the dewatering target (or $75 \mathrm{~m}$ below the depressurisation target for design). This requires an interpretive assessment of the pushback groundwater - level trends to establish whether the occurrence is a short-lived interruption to groundwater system drawdown or reflecting a broader shortfall in groundwater system responses.

- A Level-2 (intermediate) alarm is triggered where the current observed groundwater level is $30 \%$ above the dewatering target, toward the depressurisation target. This requires an immediate action plan to implement renewed drawdown in the area of concern, and a sensitivity analysis with the FLAC3D model to evaluate potential risks and options in the slope design to a minimally compliant future condition. 
- A Level-3 (highest) alarm where the current observed groundwater level is $70 \%$ above the dewatering target, toward the depressurisation target. This requires an immediate action plan to implement renewed drawdown in the area of concern, pit slope design analysis to evaluate risk and potential modification to the pushback plan, including potential slowing, additional unloading or alternate change to geometry.

In practice (during pushback implementation) the alarm system has not been triggered to date as the dewatering targets have been met and trend to compliance at all monitoring locations. However, the alarm system is in place and used within a standardised monthly dewatering report that shows the latest results and it is the main tool for proactive management of the depressurisation program and potential decisions to make additions or adjustments to the system.

\section{Conclusion}

Freeport-McMoRan Morenci is implementing a program of pushbacks in the Western Copper open pit mining area. Proactive mine dewatering and pit slope depressurisation are required to lower the groundwater table in advance of mining and 1) reduce the impact of water on general day-to-day mine-ability of the working benches, and 2) generate pit slope pore pressure conditions that comply with the annualised pit slope design and associated FoS acceptance criteria. Given the sensitivity of pit slope performance to groundwater pressure, the mine dewatering and pit slope geomechanics programs were fully integrated - from evaluation and design through to operational implementation, tracking, reconciliation and management. The integrated process has provided a very effective method for managing the pit slope depressurisation process and ensuring that proactive forecasting of future conditions is completed using the predictive groundwater flow and slope design models in combination with field monitoring data. The workflow has been proven to be a key tool for effective slope management. It is applicable and may be adopted at other mine properties with similar pit slope depressurisation requirements.

\section{Acknowledgement}

The authors acknowledge the help and support of Freeport-McMoRan Morenci's Mine Geology, Geomechanics and Mine Engineering departments in preparation of the work present within this paper.

\section{References}

Beale, G \& Read, J 2013, Guidelines for Evaluating Water in Pit Slope Stability, CSIRO Publishing, Clayton.

Doubek, GR \& Beale, G 1988, Investigation of Groundwater Characteristics Using Dual Tube Reverse Circulation Drilling, Society for Mining, Metallurgy \& Exploration, Englewood. 